\title{
The Effect of Glucose When Added to a Fat Load on the Response of Glucagon-Like Peptide-1 (GLP-1) and Apolipoprotein B-48 in the Postprandial Phase
}

\author{
K. ZEMÁNKOVÁ ${ }^{1}$, J. MRÁZKOVÁ ${ }^{1}$, J. PIŤHA ${ }^{1}$, J. KOVÁŘ ${ }^{1}$ \\ ${ }^{1}$ Laboratory for Atherosclerosis Research, Centre for Experimental Medicine, Institute for Clinical \\ and Experimental Medicine, Prague, Czech Republic
}

Received September 3, 2015

Accepted September 17, 2015

\section{Summary}

Increased and prolonged postprandial lipemia has been identified as a risk factor of cardiovascular disease. However, there is no consensus on how to test postprandial lipemia, especially with respect to the composition of an experimental meal. To address this question of how glucose, when added to a fat load, affects the selected parameters of postprandial lipemia, we carried out a study in 30 healthy male volunteers. Men consumed an experimental meal containing either $75 \mathrm{~g}$ of fat $+25 \mathrm{~g}$ of glucose ( $\mathrm{F}+\mathrm{G}$ meal) or $75 \mathrm{~g}$ of fat ( $\mathrm{F}$ meal) in a control experiment. Blood was taken before the meal and at selected time points within the following $8 \mathrm{~h}$. Glucose, when added to a fat load, induced an increase of glycemia and insulinemia and, surprisingly, a $20 \%$ reduction in the response of both total and active glucagon-like peptide-1 (GLP-1) concentration. The addition of glucose did not affect the magnitude of postprandial triglyceridemia and TRL-C and TRL-TG concentrations but stimulated a faster response of chylomicrons to the test meal, evaluated by changes in apolipoprotein B-48 concentrations. The addition of glucose induced the physiological response of insulin and the lower response of GLP-1 to the test meal during the early postprandial phase, but had no effect on changes of TRL-cholesterol and TRL-TG within $8 \mathrm{~h}$ after the meal.

\section{Key words}

Postprandial lipemia • Triglyceride • Glucose • GLP-1 • Insulin

\section{Corresponding author}

K. Zemánková, Institute for Clinical and Experimental Medicine, Laboratory for Atherosclerosis Research, Vídeňská 1958/9, 14021 Prague 4, Czech Republic. E-mail: katerina.zemankova@ikem.cz

\section{Introduction}

Increased triglyceride (TG) concentration is generally accepted as a risk factor for ischemic heart disease and, according to recent guidelines, lowering TG has become a therapeutic target for reducing cardiovascular disease risk. There is evidence that triglyceride-rich lipoproteins (TRL) and their remnants are directly involved in the pathogenesis of atherosclerosis (Chapman et al. 2011).

Traditionally, TG concentration is measured in the fasting state (8-12 $\mathrm{h}$ after overnight fasting) mainly because the rise in TG levels after a meal exhibits a high variation (Kolovou et al. 2011). Recent data from The Copenhagen City Heart Study and other studies point out that non-fasting TG concentration is more closely associated with cardiovascular disease risk than fasting TG concentration (Nordestgaard et al. 2007, Freiberg et al. 2008, Mora et al. 2008). It should be pointed out that humans spend the larger part of the day in a postprandial state.

Analogous to the oral glucose tolerance test, it would be convenient to administer a fat tolerance test to reveal subjects with defective TRL metabolism. It has been shown in a number of studies that the magnitude of postprandial lipemia is affected by diet, physical activity, genetic factors, and by the amount and composition of the experimental meal (Lairon 1996, Annuzzi 2008). However, the interpretation of the results of these studies is complicated due to the use of very different experimental designs. Moreover, most of these studies do not pay attention to the fact that the metabolism of 
nutrients in the postprandial phase is controlled by changes in the hormonal milieu induced by the nutrients themselves. For example, insulin secretion should inhibit lipolysis in adipose tissue and affect lipoprotein lipase (LPL) activity in such a way that TG is preferentially hydrolyzed and uptaken in adipose tissue, not in the muscle (Goldberg et al. 2009, Kersten 2014). Although the administration of fat alone stimulates insulin secretion (Lindgren et al. 2011), its effect is only negligible compared to the insulin response to glucose administration. It is not quite clear how the addition of a relatively small amount of glucose (which induces the physiological insulin response) affects the magnitude and duration of postprandial lipemia. To address such a question, we studied the effect of the addition of $25 \mathrm{~g}$ of glucose to $75 \mathrm{~g}$ of fat on selected parameters of postprandial lipemia for $8 \mathrm{~h}$ in 30 healthy volunteers. The composition of the test meal was close to that recommended by an expert panel in 2011 (Kolovou et al. 2011). Moreover, we also analyzed the effect of the addition of glucose on the concentration of glucagon-like peptide-1 (GLP-1), another important player in the regulation of hormonal secretion in the postprandial state (Holst 2007).

\section{Methods}

\section{Subjects}

Thirty healthy male volunteers with triglyceridemia lower than $2.5 \mathrm{mmol} / \mathrm{l}$ (Table 1) were included in the study. All participants gave written informed consent and the study was approved by the Ethics Committee of the Institute for Clinical and Experimental Medicine and Thomayer Hospital in Prague. All work was conducted in compliance with the principles of the Declaration of Helsinki.

Table 1. Characteristics of volunteers.

\begin{tabular}{lc}
\hline Characteristic & Mean \pm SD \\
\hline Age [years] & $34.0 \pm 8.2$ \\
BMI [kg/m $\left.{ }^{2}\right]$ & $26.1 \pm 3.2$ \\
Waist $[\mathrm{cm}]$ & $92.1 \pm 9.8$ \\
Hip [cm] & $101.4 \pm 6.8$ \\
Glucose [mmol/l] & $5.5 \pm 0.5$ \\
Total cholesterol [mmol/l] & $4.41 \pm 0.75$ \\
TG [mmol/l] & $1.10 \pm 0.49$ \\
\hline
\end{tabular}

Data are presented as mean $\pm S D(n=30)$.

\section{Study design}

Two experiments were carried out in each of the volunteers. In one experiment the volunteers consumed a test meal consisting of $75 \mathrm{~g}$ of fat $(225 \mathrm{ml}$ of $30 \%$ whipping cream) and $25 \mathrm{~g}$ of glucose $(3240 \mathrm{~kJ})$; in the control experiment the volunteers consumed just $75 \mathrm{~g}$ of fat $(2830 \mathrm{~kJ})$. Participants were asked to avoid alcohol $24 \mathrm{~h}$ before the study and to consume their last evening meal by 9 p.m. at the latest. The order of both experiments was randomized and they were carried out with an interval lasting at least 2 weeks.

At the beginning of each part, a cannula for collecting blood samples was inserted into the antecubital vein of the forearm. The first blood sample was obtained and the test meal was consumed within $5 \mathrm{~min}$. Other blood samples were obtained 0.5, 1, 1.5, 2, 4, 6 and $8 \mathrm{~h}$ after the test meal. After the last blood collection, $8 \mathrm{~h}$ after meal consumption, heparin (Léčiva, Prague, Czech Republic) was injected intravenously at a dose of $100 \mathrm{IU} / \mathrm{kg}$ and $10 \mathrm{~min}$ later blood was taken for determination of LPL mass in post-heparin plasma. During the tests, volunteers could drink only water and were not allowed to eat any food.

\section{Biochemical methods}

Blood samples for plasma TG, cholesterol, HDL-cholesterol, LDL-cholesterol, free fatty acids (FFA), glucose, insulin, apoB-48 and GLP-1 concentrations were collected in EDTA vacutainer tubes. Aliquots of blood for measurement of active GLP-1 concentration were collected according to manufacturer instructions. Post-heparin plasma was collected into heparinized vacutainer tubes. Aliquots of plasma acquired at all time points were stored frozen at $-80^{\circ} \mathrm{C}$ until analyzed.

The concentrations of TG and cholesterol in plasma were measured using enzymatic kits (Roche Diagnostics, Mannheim, Germany), glucose concentration was measured using a kit from PLIVA Lachema Diagnostika (Brno, Czech Republic) and FFA were measured using a kit from Wako Chemicals $\mathrm{GmbH}$ (Germany). Plasma insulin levels were measured using IRMA (Immunotech, Beckman Coulter, Prague, Czech Republic). Apolipoprotein B-48 concentrations in plasma and in triglyceride-rich lipoproteins (TRL) were measured using a human ApoB-48 ELISA kit (Shibayagi Co., Ltd., Shibukawa, Japan). Total apolipoprotein B concentration in the TRL fraction was measured using an Apolipoprotein B Human ELISA kit (Abcam plc, United 
Kingdom). Concentrations of total and active GLP-1 were measured using ELISA kits (EMD Millipore, Missouri, USA). These parameters were measured at all time points.

TRL were isolated from plasma obtained at 0,1 , 2, 4, 6 and 8 h by ultracentrifugation (Havel et al. 1955). Cholesterol and TG in TRL were measured using enzymatic kits as described above. LPL mass was measured in heparinized plasma collected at the end of each test using ELISA kits (Alpco Immunoassays, Salem, USA).

\section{Statistical analyses}

The differences between changes of parameters under the study were evaluated using ANOVA for repeated measurements (JMP ${ }^{\circledR}$ 10.0.0, SAS Institute Inc.) and corresponding post-hoc tests were carried out where significant differences were found. The areas under curves were compared by the paired t-test using GraphPadInStat.

\section{Results}

The addition of $25 \mathrm{~g}$ of glucose to a $75 \mathrm{~g}$ fat load induced a $19 \%$ increase in glycemia and a corresponding 4.5-fold increase in insulinemia, both peaking $30 \mathrm{~min}$ after the meal (Fig. 1). Glycemia did not rise after the pure fat load and only a relatively small increment in insulin concentration was observed (Fig. 1). The concentration of both total GLP-1 and the active form of GLP-1 increased after the meal. The addition of glucose to the fat load resulted in an approx. $22 \%$ reduction of the total GLP-1 response and an $18 \%$ reduction of the active GLP-1 response during the first two hours after the meal (Fig. 1).

The consumption of $75 \mathrm{~g}$ of fat induced a significant increase in triglyceridemia peaking between 2 and $4 \mathrm{~h}$ (Fig. 2). The course and magnitude of postprandial hypertriglyceridemia were not affected by the added glucose. The same applies for the changes in concentration of cholesterol and triglyceride in triglyceride-rich lipoproteins (TRL) $\quad(\mathrm{d}<1.006 \mathrm{~g} / \mathrm{ml})$ (Table 2). The magnitude of the response of both plasma and TRL apolipoprotein B-48 (apoB-48) concentrations to the fat load did not differ between both experiments. However, using ANOVA for repeated measures it was demonstrated that the course of changes in apoB-48 concentrations differed between both experiments - the apoB-48 response was faster after glucose addition. No differences between both experiments were observed for changes in TRL-apoB concentrations, which included both hepatic apoB-100 and intestinal apoB-48. The course of free fatty acid (FFA) concentrations did not differ statistically significantly between both experiments, although the statistically significant decrease of FFA concentration was observed after glucose.

Finally, LPL mass in post-heparin plasma collected $8 \mathrm{~h}$ after the meal did not differ between $\mathrm{F}$ and $\mathrm{F}+\mathrm{G}$ experiments $(503 \pm 102$ vs. $476 \pm 95 \mathrm{ng} / \mathrm{ml}$, respectively).
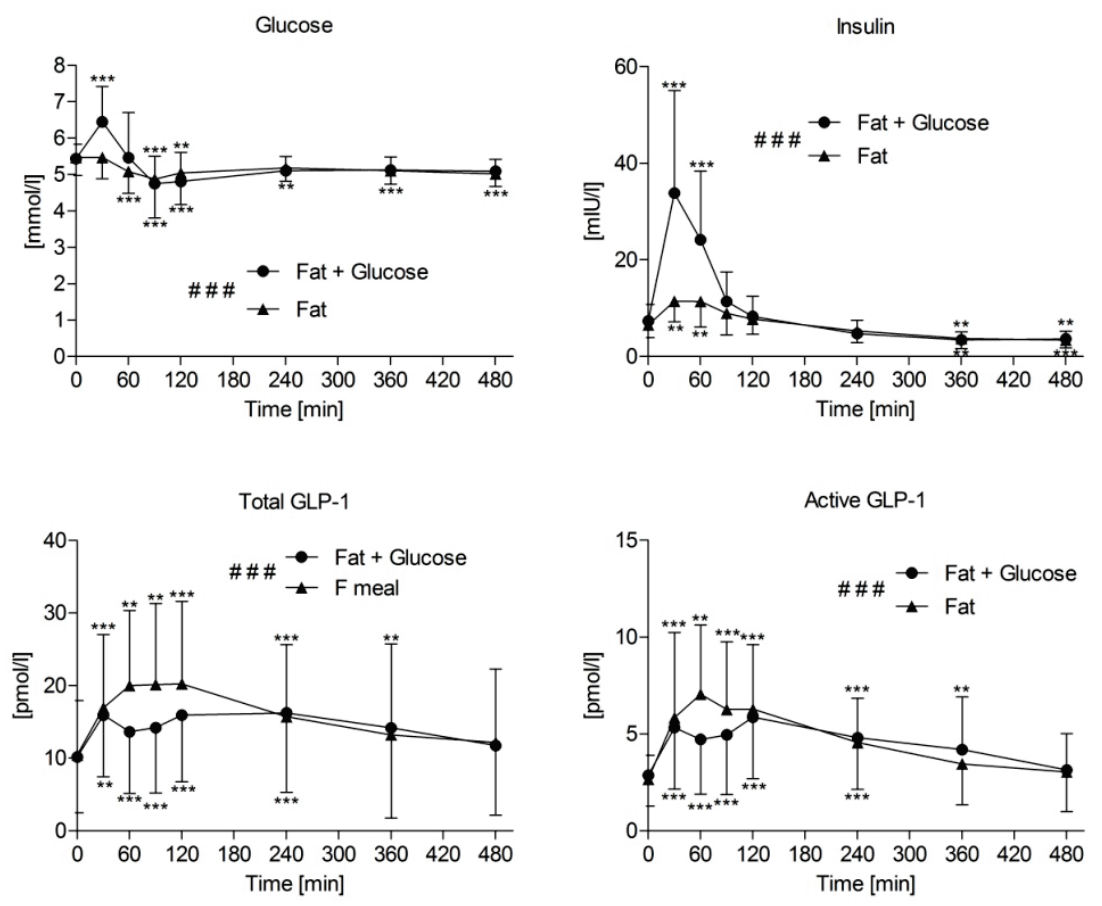

Fig. 1. Concentrations of glucose, insulin and total and active glucagon-like peptide 1 (GLP-1). Data are presented as mean \pm SD $(n=30)$. \#\#\# $p<0.001$ for differences between both curves as evaluated by ANOVA for repeated measures; ${ }^{* *} p<0.01$, ${ }^{* * *} p<0.001$ vs. baseline. 


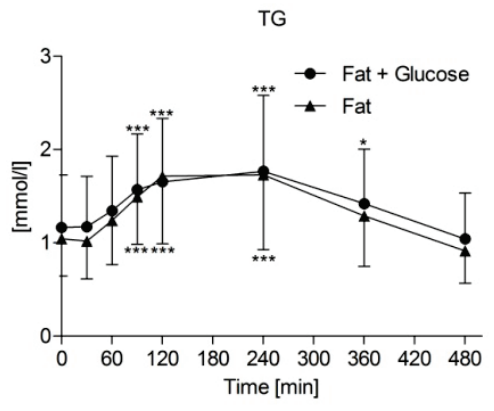

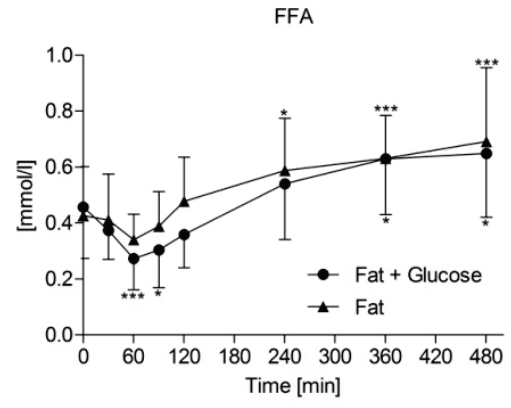

Fig. 2. Concentrations of triglyceride (TG), free fatty acids (FFA), plasma and triglyceride-rich lipoproteins (TRL) apolipoprotein B-48 (apoB-48). Data are presented as mean \pm SD $(n=30) .{ }^{*} p<0.05$, $\#$ \# $<0.01$ for differences between both curves as evaluated by ANOVA for repeated measures; ${ }^{*} p<0.05,{ }^{* * *} p<0.001$ vs. baseline.
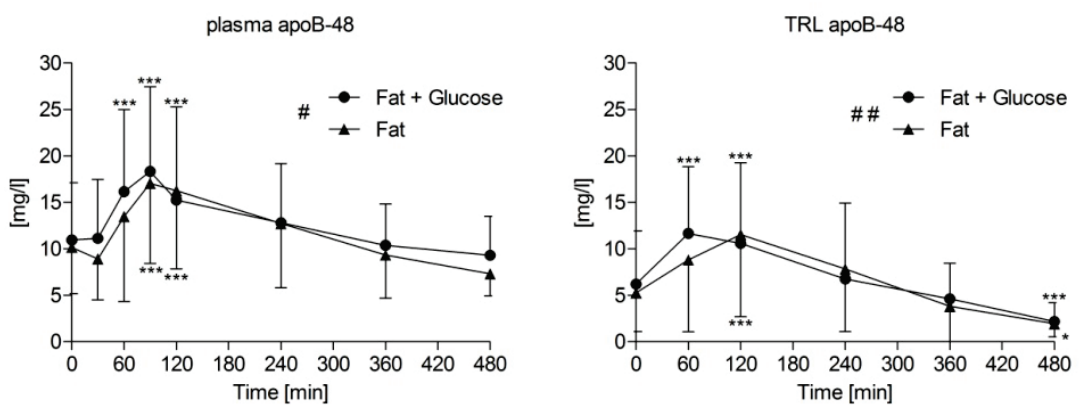

Table 2. Areas under curves (AUC) of selected parameters during postprandial lipemia.

\begin{tabular}{|c|c|c|c|c|c|c|c|c|c|}
\hline \multirow[b]{2}{*}{ Parameter } & \multicolumn{2}{|c|}{$\operatorname{AUC}(0-8 \mathrm{~h})$} & \multirow[b]{2}{*}{ t-test } & \multicolumn{2}{|c|}{2 h AUC (0-2 h) } & \multicolumn{4}{|c|}{4 h AUC (0-4 h) } \\
\hline & $\mathbf{F}+\mathbf{G}$ & $\mathbf{F}$ & & $\mathbf{F}+\mathbf{G}$ & $\mathbf{F}$ & t-test & $\mathbf{F}+\mathbf{G}$ & $\mathbf{F}$ & t-test \\
\hline$T G\left[\mathrm{mmol}^{*} \mathrm{~h} / \mathrm{l}\right]$ & $11.8 \pm 4.7$ & $11.2 \pm 4.1$ & n.s. & & & & & & \\
\hline$T R L-T G\left[\mathrm{mmol}^{*} \mathrm{~h} / \mathrm{l}\right]$ & $8.5 \pm 4.2$ & $8.6 \pm 3.8$ & n.s. & & & & & & \\
\hline Cholesterol [mmol*h/l] & $35.7 \pm 6.8$ & $34.7 \pm 5.4$ & n.s. & & & & & & \\
\hline FFA $[\mathrm{mmol} * h / l]$ & $4.0 \pm 1.0$ & $4.4 \pm 1.2$ & n.s. & & & & & & \\
\hline Glucose [mmol*h/l] & & & & $37.7 \pm 5.8$ & $34.09 \pm 3.5$ & 0.001 & $43.8 \pm 6.3$ & $43.0 \pm 4.3$ & n.s. \\
\hline Insulin $\left[m I U^{*} h / l\right]$ & & & & $37.9 \pm 17.3$ & $19.2 \pm 6.7$ & $<0.001$ & $51.0 \pm 22.4$ & $31.2 \pm 10.6$ & $<0.001$ \\
\hline GLP-1 Total [pmol*h/l] & & & & $28.4 \pm 16.4$ & $36.2 \pm 19.1$ & $<0.001$ & $59.6 \pm 32.5$ & $71.6 \pm 38.6$ & 0.001 \\
\hline GLP-1 Active $[p m o l * h / l]$ & & & & $9.7 \pm 5.2$ & $11.8 \pm 5.7$ & $<0.001$ & $20.4 \pm 9.4$ & $22.7 \pm 10.5$ & 0.024 \\
\hline ApoB-48 [mg*h/l] & $100.4 \pm 43.4$ & $94.1 \pm 42.9$ & n.s. & & & & & & \\
\hline$A p o B-48$ TRL [mg*h/l] & $55.6 \pm 38.2$ & $54.0 \pm 36.0$ & n.s. & & & & & & \\
\hline$A p o B[m g * h / l]$ & $710.1 \pm 432.8$ & $662.3 \pm 374.5$ & n.s. & & & & & & \\
\hline
\end{tabular}

Data are presented as mean \pm SD $(n=30)$.

\section{Discussion}

In this study of young healthy volunteers, we demonstrate that the addition of $25 \mathrm{~g}$ of glucose to a fat load induced an expected physiological increase of glycemia and insulinemia and, surprisingly, a suppression of GLP-1 response compared to a fat load alone. The addition of glucose did not affect the magnitude and duration of postprandial triglyceridemia and TRL-C and TRL-TG concentrations. However, it did stimulate a faster response of chylomicrons to the test meal as evaluated on the basis of changes in apolipoprotein B-48 concentrations.

GLP-1 is recognized as an important signaling molecule which potentiates insulin secretion. It is secreted from enteroendocrine L-cells after stimulation with nutrients (carbohydrate, lipid, protein) and bile salts (Ezcurra et al. 2013). GLP-1 acts as an insulinotropic peptide in a glucose-dependent manner only (Holz 2004), a finding for which our results provide elegant support. In our study, even though the F meal induced a higher GLP-1 response, it did not induce an insulin response compared to the $\mathrm{F}+\mathrm{G}$ meal.

The findings that both active and total GLP-1 secretion are suppressed when glucose is added to a fat load are rather surprising. Whereas active GLP-1 represents the metabolically active incretin, total GLP-1 
also comprises the molecules that are inactivated by the proteolytic action of dipeptidyl peptidase-4 (DPP-4). Due to the very short half-life of active GLP-1, total GLP-1 concentration is considered a better marker of GLP-1 secretion (Holst 2007). Due to the similar course of both the active and total GLP-1 response, we can assume that glucose addition to a fat load directly affects GLP-1 production.

It has been described that both glucose and fat induce a GLP-1 response (Carr et al. 2008, Herrmann et al. 1995) and that they use independent regulatory pathways to stimulate GLP-1 secretion by intestinal L-cells (Ezcurra et al. 2013). Consequently, the combination of fat and glucose should not diminish GLP-1 secretion. However, to the best of our knowledge, no experimental data address the question of the effect of a similar combination of two nutrients. We can only speculate why the addition of glucose to a fat load suppresses the GLP-1 response. First, glucose added to a test meal could slow down gastric emptying (Cohen and Berger 1990), but it is unlikely because it should also slow down the beginning of postprandial changes in triglyceridemia. Second, there might be an earlier peak of GLP-1 concentration after the $\mathrm{F}+\mathrm{G}$ meal even though this is also highly unlikely - no such peak has been observed in studies that used different nutrients to induce an incretin response, including mixed meals (Carr et al. 2008, Herrmann et al. 1995). Third, we can speculate that glucose ingestion can activate the feedback inhibition of GLP-1 secretion by hyperglycemia and/or hyperinsulinemia. For example, Vollmer et al. (2009) reported that acute hyperglycemia during hyperglycemic clamp reduces postprandial GLP-1 levels by approximately $50 \%$. However, it cannot be excluded from their data that hyperinsulinemia also plays a role in feedback inhibition of GLP-1 secretion. A 45-min infusion of insulin at the beginning of their experiments resulted in a $15-20 \%$ reduction of GLP-1 concentration.

It is recognized that hypertriglyceridemia in the postprandial phase results from the accumulation of TRL of both intestinal and hepatic origin. The addition of $25 \mathrm{~g}$ of glucose to a fat load neither had an effect on the magnitude and duration of postprandial triglyceridemia nor on the concentration of TRL-C and TRL-TG. This is in contrast to a previous study which showed that glucose addition reduced the magnitude of postprandial lipemia in a dose-dependent manner (Cohen and Berger 1990). In their study, glucose ingestion resulted in delayed gastric emptying and decreased VLDL production. The differences between their and our results could be explained by the lower glucose dose (50 g and $100 \mathrm{~g}$ vs. $25 \mathrm{~g}$ of glucose, respectively) and higher fat load (40 g vs. $75 \mathrm{~g}$ of fat, respectively) in our study. As stated above, it does not seem likely that decelerated gastric emptying could take place under the conditions of our study. FFA concentration is believed to be a major determinant of the VLDL production rate (Lewis 1997). However, there was no statistically significant difference in the AUC of FFA despite the mild suppression of FFA concentration in the early postprandial phase after the $\mathrm{F}+\mathrm{G}$ meal, which suggests that the VLDL production rate may not be significantly affected in our experiment. Another important determinant of magnitude of postprandial lipemia is the amount and activity of lipoprotein lipase, the rate-limiting factor of TRL-TG clearance from circulation. However, LPL mass was not affected by glucose when added to a fat load. Therefore, the glucose in the amount used in our study ( $25 \mathrm{~g}$ ) was not enough to induce marked changes in VLDL production and metabolism. In support of that, we did not observe any differences in TRL apoB between both experiments (Table 3).

Table 3. Changes in triglyceride-rich lipoproteins (TRL) concentrations during postprandial lipemia.

\begin{tabular}{|c|c|c|c|c|c|c|c|c|}
\hline Time [h] & & $\mathbf{0}$ & 1 & 2 & 4 & 6 & 8 & ANOVA \\
\hline$T R L-T G$ & $\mathrm{~F}+\mathrm{G}$ & $0.77 \pm 0.49$ & $1.03 \pm 0.51 * *$ & $1.23 \pm 0.62 * * *$ & $1.32 \pm 0.73 * * *$ & $1.01 \pm 0.51 *$ & $0.64 \pm 0.41$ & \multirow{2}{*}{ n.s. } \\
\hline$[\mathrm{mmol} / \mathrm{l}]$ & $\mathrm{F}$ & $0.73 \pm 0.38$ & $0.94 \pm 0.45$ & $1.34 \pm 0.59 * * *$ & $1.40 \pm 0.75^{* * *}$ & $0.94 \pm 0.49$ & $0.58 \pm 0.32$ & \\
\hline$T R L-C$ & $\mathrm{~F}+\mathrm{G}$ & $0.31 \pm 0.21$ & $0.33 \pm 0.20$ & $0.34 \pm 0.20$ & $0.39 \pm 0.24^{* *}$ & $0.34 \pm 0.22$ & $0.23 \pm 0.17^{*}$ & \multirow[b]{2}{*}{ n.s. } \\
\hline$[\mathrm{mmol} / \mathrm{ll}]$ & $\mathrm{F}$ & $0.29 \pm 0.15$ & $0.31 \pm 0.15$ & $0.34 \pm 0.16^{*}$ & $0.38 \pm 0.19 * *$ & $0.30 \pm 0.18$ & $0.20 \pm 0.14^{*}$ & \\
\hline TRL ApoB & $\mathrm{F}+\mathrm{G}$ & $90.01 \pm 55.70$ & $85.49 \pm 52.10$ & $88.01 \pm 52.74$ & $93.31 \pm 55.28$ & $91.72 \pm 69.00$ & $77.49 \pm 60.25 *$ & \multirow[b]{2}{*}{ n.s. } \\
\hline$[\mathrm{mg} / \mathrm{l}]$ & $\mathrm{F}$ & $89.24 \pm 47.07$ & $88.23 \pm 44.96$ & $81.46 \pm 47.27$ & $88.39 \pm 49.96$ & $82.11 \pm 57.87$ & $66.29 \pm 47.63 * *$ & \\
\hline
\end{tabular}

Data are presented as mean $\pm S D(n=30) . * p<0.05, * * p<0.01, * * * p<0.001$ against time 0 . ANOVA - the statistical significance for differences between the $F+G$ meal and the $F$ meal is evaluated using ANOVA for repeated measures. 
In spite of there being no differences during the course of postprandial triglyceridemia, the ANOVA for repeated measures detected differences during the course of changes in plasma and TRL apoB-48 concentrations between both experiments. ApoB-48 concentration (and thus a number of chylomicron particles) rose in plasma earlier after the $\mathrm{F}+\mathrm{G}$ meal. Previous work has shown that some TG remains in the enterocytes after each meal and that these TG are secreted from the intestine very quickly after glucose administration (Robertson et al. 2003). It has been demonstrated that glucose ingestion $5 \mathrm{~h}$ after a fatty meal mobilizes lipid droplets in enterocytes, eliciting an elevation in plasma TG and apoB-48. It has also been demonstrated that glucose can directly increase lipid-stimulated chylomicron particle production independent of changes in pancreatic hormones or gastric emptying (Xiao et al. 2013). Moreover, a mixed meal with a high glycemic index results in higher apoB-48 concentrations when compared with a meal with a low glycemic index (Harbis et al. 2001).

Currently, there is no consensus on the design of postprandial lipemia-testing with respect to the composition of the test meal, especially in relation to the content of nutrients other than fat. Our data suggest that the addition of $25 \mathrm{~g}$ of glucose to $75 \mathrm{~g}$ of dairy fat does not diminish the magnitude of postprandial lipemia compared to higher glucose loads and that it induces the physiological response of insulin. For this reason, this design might be suitable for the measurement of postprandial lipemia in clinical studies.

In conclusion, the addition of $25 \mathrm{~g}$ of glucose to a fat load induced an expected physiological increase of glycemia and insulinemia and, surprisingly, a suppression of GLP-1 response compared to a fat load alone. The mechanism of such an effect of glucose addition remains to be determined. The addition of glucose did not affect the magnitude and duration of postprandial triglyceridemia and TRL-C and TRL-TG concentrations, although it did stimulate a faster response of chylomicrons to the test meal, as evaluated on the basis of changes in apoB-48 concentrations.

\section{Conflict of Interest}

There is no conflict of interest.

\section{Acknowledgements}

This project was supported by grant no. NT 140273/2013 from IGA MH CR. The Centre for Experimental Medicine (IKEM) received financial support from the European Commission within the Operational Programme, Prague-Competitiveness; project "CEVKOON" (\#CZ.2.16/3.1.00/22126). The authors wish to thank Monika Fiedlerová, Dana Körberová and Regina Stupalová for their excellent technical assistance and Věra Lánská for the statistical analysis.

\section{References}

ANNUZZI G: Genetic and environmental modulation of postprandial lipemia: from a better knowledge of the mechanisms to a more effective treatment strategy. Nutr Metab Cardiovasc Dis 18: 169-172, 2008.

CARR RD, LARSEN MO, WINZELL MS, JELIC K, LINDGREN O, DEACON CF, AHREN B: Incretin and islet hormonal responses to fat and protein ingestion in healthy men. Am J Physiol Endocrinol Metab 295: E779E784, 2008.

CHAPMAN MJ, GINSBERG HN, AMARENCO P, ANDREOTTI F, BOREN J, CATAPANO AL, DESCAMPS OS, FISHER E, KOVANEN PT, KUIVENHOVEN JA, LESNIK P, MASANA L, NORDESTGAARD BG, RAY KK, REINER Z, TASKINEN MR, TOKGOZOGLU L, TYBJAERG-HANSEN A, WATTS GF: Triglyceriderich lipoproteins and high-density lipoprotein cholesterol in patients at high risk of cardiovascular disease: evidence and guidance for management. Eur Heart J 32: 1345-1361, 2011.

COHEN JC, BERGER GM: Effects of glucose ingestion on postprandial lipemia and triglyceride clearance in humans. J Lipid Res 31: 597-602, 1990.

EZCURRA M, REIMANN F, GRIBBLE FM, EMERY E: Molecular mechanisms of incretin hormone secretion. Curr Opin Pharmacol 13: 922-927, 2013.

FREIBERG JJ, TYBJAERG-HANSEN A, JENSEN JS, NORDESTGAARD BG: Nonfasting triglycerides and risk of ischemic stroke in the general population. JAMA 300: 2142-2152, 2008.

GOLDBERG IJ, ECKEL RH, ABUMRAD NA: Regulation of fatty acid uptake into tissues: lipoprotein lipase- and CD36-mediated pathways. J Lipid Res 50 (Suppl): S86-S90, 2009. 
HARBIS A, DEFOORT C, NARBONNE H, JUHEL C, SENFT M, LATGE C, DELENNE B, PORTUGAL H, ATLAN-GEPNER C, VIALETTES B, LAIRON D: Acute hyperinsulinism modulates plasma apolipoprotein B-48 triglyceride-rich lipoproteins in healthy subjects during the postprandial period. Diabetes 50: 462-469, 2001.

HAVEL RJ, EDER HA, BRAGDON JH: The distribution and chemical composition of ultracentrifugally separated lipoproteins in human serum. $J$ Clin Invest 34: 1345-1353, 1955.

HERRMANN C, GOKE R, RICHTER G, FEHMANN HC, ARNOLD R, GOKE B: Glucagon-like peptide-1 and glucose-dependent insulin-releasing polypeptide plasma levels in response to nutrients. Digestion 56: 117-126, 1995.

HOLST JJ: The physiology of glucagon-like peptide 1. Physiol Rev 87: 1409-1439, 2007.

HOLZ GG: New insights concerning the glucose-dependent insulin secretagogue action of glucagon-like peptide-1 in pancreatic beta-cells. Horm Metab Res 36: 787-794, 2004.

KERSTEN S: Physiological regulation of lipoprotein lipase. Biochim Biophys Acta 1841: 919-933, 2014.

KOLOVOU GD, MIKHAILIDIS DP, KOVAR J, LAIRON D, NORDESTGAARD BG, OOI TC, PEREZ-MARTINEZ P, BILIANOU H, ANAGNOSTOPOULOU K, PANOTOPOULOS G: Assessment and clinical relevance of non-fasting and postprandial triglycerides: an expert panel statement. Curr Vasc Pharmacol 9: 258-270, 2011.

LAIRON D: Lipid absorption and metabolism: physiological and molecular aspects. Proc Nutr Soc 55: 1-3, 1996.

LEWIS GF: Fatty acid regulation of very low density lipoprotein production. Curr Opin Lipidol 8: 146-153, 1997.

LINDGREN O, CARR RD, DEACON CF, HOLST JJ, PACINI G, MARI A, AHREN B: Incretin hormone and insulin responses to oral versus intravenous lipid administration in humans. $J$ Clin Endocrinol Metab 96: 2519-2524, 2011.

MORA S, RIFAI N, BURING JE, RIDKER PM: Fasting compared with nonfasting lipids and apolipoproteins for predicting incident cardiovascular events. Circulation 118: 993-1001, 2008.

NORDESTGAARD BG, BENN M, SCHNOHR P, TYBJAERG-HANSEN A: Nonfasting triglycerides and risk of myocardial infarction, ischemic heart disease, and death in men and women. JAMA 298: 299-308, 2007.

ROBERTSON MD, PARKES M, WARREN BF, FERGUSON DJ, JACKSON KG, JEWELL DP, FRAYN KN: Mobilisation of enterocyte fat stores by oral glucose in humans. Gut 52: 834-839, 2003.

VOLLMER K, GARDIWAL H, MENGE BA, GOETZE O, DEACON CF, SCHMIDT WE, HOLST JJ, MEIER JJ: Hyperglycemia acutely lowers the postprandial excursions of glucagon-like peptide-1 and gastric inhibitory polypeptide in humans. J Clin Endocrinol Metab 94: 1379-1385, 2009.

XIAO C, DASH S, MORGANTINI C, LEWIS GF: Novel role of enteral monosaccharides in intestinal lipoprotein production in healthy humans. Arterioscler Thromb Vasc Biol 33: 1056-1062, 2013. 